\title{
Beta-Thalassemia Presenting as an Acute Neurological Complication: A Case Report
}

\author{
Vinaya Gaduputia, Jayanthi Loganathan ${ }^{\mathrm{a}}$, Suresh Kumar Nayudu ${ }^{\mathrm{a}, \mathrm{b}}$, Sridhar Chilimuri ${ }^{\mathrm{a}}$
}

\begin{abstract}
Beta-thalassemia is an inherited defect in the rate of synthesis of one or more beta-globin chains of hemoglobin resulting in anemia, hemolysis and ineffective erythropoeisis. Extramedullary hematopoietic tumors may develop in extreme cases of dyserythropoiesis. Acute neurological complications in patients with beta-thalassemia have been reported in association with cerebral ischemia, spinal cord fractures and compression from extramedullary hematopoietic tumors. However extramedullary hematopeietic tumors in the setting of acute blood loss leading to neurological complications have never been reported. We report this case of a 27-year-old woman with beta-thalassemia who presented with acute neurological deficit during immediate postoperative period of cesarean section associated with significant drop in hemoglobin. The Magnetic Resonance Imaging of the thoracic and lumbosacral spine revealed compressive intra-spinal and para-spinal extra-medullary hematopoietic tissue. Patient's symptoms improved dramatically with conservative management.
\end{abstract}

Keywords: Beta-thalassemia; Acute neurological complications

\section{Introduction}

Thalassemias consist of inherited defects in the rate of synthesis of one or more of the globin chains of hemoglobin [1]. Beta-thalassemia is a condition of impaired production

Manuscript accepted for publication February 4, 2011

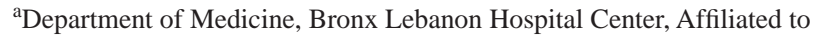
Albert Einstein College of Medicine, Bronx, New York, USA

${ }^{\mathrm{b} C o r r e s p o n d i n g ~ a u t h o r: ~ S u r e s h ~ K u m a r ~ N a y u d u, ~ D e p a r t m e n t ~ o f ~}$ Medicine, 1650 Selwyn Avenue, \#17B, Bronx, NY-10457, USA. Email: sureshnayudu@live.com

doi:10.4021/jmc133w of beta globin chains to varying degree, leading to a relative excess of alpha globin chains, which precipitate within the cell [2]. The resultant anemia, hemolysis and ineffective erythropoiesis form the fundamental pathology for clinical manifestations of beta-thalassemia. In extreme cases of dyserythropoiesis, extra-medullary hematopoietic tumors may develop [3-6]. Acute neurological complications in patients with beta-thalassemia have been reported in association with cerebral ischemia, spinal cord fractures and compression from extra-medullary hematopoietic tumors [7-11]. Other hematological disorders such as leukemias are also reported to have acute neurological complications [12-14]. Review of literature has shown that the neurological complications have been reported with higher frequency in association with thalassemia intermedia $[15,16]$. To our knowledge there are no reports of patients in whom hemodynamic shifts during surgery caused a sudden surge in extra-medullary hematopoiesis leading to clinical complications.

\section{Case Report}

A 27-year-old African woman from Liberia presented to the hospital with 41 weeks of gestation. The patient was scheduled for an elective cesarean section under epidural anesthesia. The surgery was unremarkable and she delivered a healthy baby. However, four hours into the post-operative period the patient noticed complete loss of sensation and power in the left lower extremity. Physical examination revealed stable vital signs and unremarkable cardiopulmonary system. Abdominal examination revealed massive non-tender hepatosplenomegaly. Evaluation of nervous system revealed normal higher functions and cranial nerves. Sensory system showed loss of sensation in all modalities from L1 to L4 and partial involvement of L5 dermatome. Motor system revealed profound weakness in the left lower extremity, sparing anterior half of the foot. Deep tendon reflexes were normal on right side but left knee reflex was absent with preserved left ankle reflex. There was no saddle anesthesia, bowel or bladder incontinence which implied patchy involvement of spinal nerve roots. Laboratory studies revealed an acute drop in hemoglobin concentration from $10 \mathrm{~g} /$ 


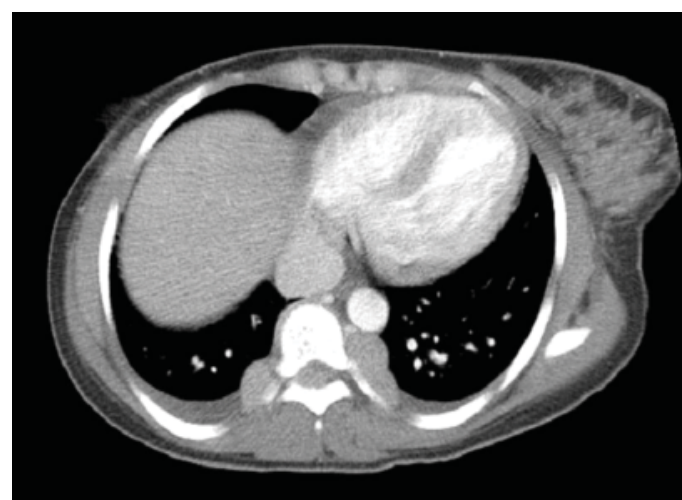

Figure 1. Bilateral para-spinal soft tissue masses consistent with extra-medullary hematopoietic tissue.

dl pre-operatively to $7.1 \mathrm{~g} / \mathrm{dl}$ after the surgery within a span of about 30 hours. The patient underwent a Computerized Tomography (CT) scan of abdomen and pelvis with contrast to evaluate intra abdominal hematoma, which incidentally revealed diffuse coarse trabeculations of the visualized osseous structures, predominantly in the sacrum, with evidence of mild bony destruction and infiltration by soft tissue suggestive of possible extra-medullary hematopoiesis (Fig. 1, 2). The Magnetic Resonance Imaging (MRI) of the thoracic and lumbosacral spine with Gadolinium revealed intraspinal soft tissue deposits from T4 to T9 and L5 to S2 level resulting in significant extra-dural compression. There were also para-spinal nodular soft tissue deposits reported from

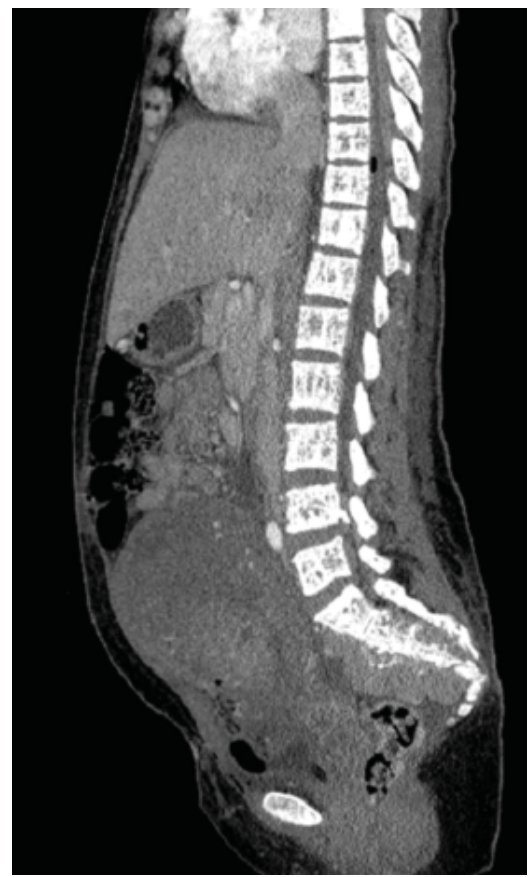

Figure 2. Pre-sacral soft tissue mass.

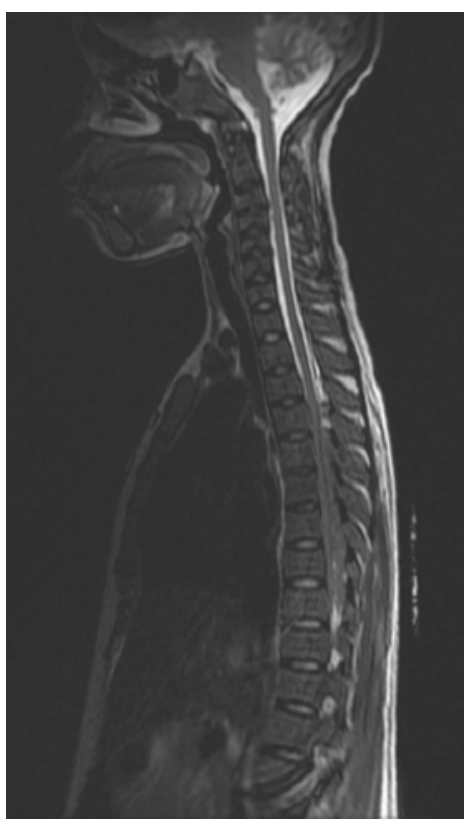

Figure 3. Sagittal T2 weighted MRI showing extra-dural compression of spinal cord by soft tissue masses involving T4 to T8 segments.

approximately T7 to T10 and L5 to S2 vertebral levels. The appearance of bone marrow on MRI was suggestive of generalized systemic marrow disorder with a lack of normal fat signal intensity compatible with clinically significant betathalassemia (Fig. 3, 4, 5). Packed Red Blood Cell transfusions were recommended, however the patient refused. The patient was started on intravenous Dexamethasone at a bolus dose of $10 \mathrm{mg}$ followed by $4 \mathrm{mg}$ every 6 hours for 3 days. The neurological examination improved dramatically with complete resolution of symptoms upon stabilization of the hemoglobin level.

\section{Discussion}

We present a young woman with history of thalassemia who presented with acute neurological complications after Caesarian section. Differential diagnoses of such presentation include (1) epidural hematoma as a complication of epidural anesthesia causing a secondary compression of the nerve roots, (2) femoral nerve entrapment, (3) vertebral compression fracture and (4) a direct compressive effect on the spinal cord from extra-medullary hematopoietic tissue [3-5, 10, 15, $17,18]$. Imaging studies did not reveal epidural hematoma or a spinal compression fracture. Femoral nerve compression occurs usually secondary to lithotomy position during normal vaginal delivery. The extent of the disease clearly indicates the chronicity of the extra-medullary hematopoietic process. However the acuity of onset puzzled us. We 


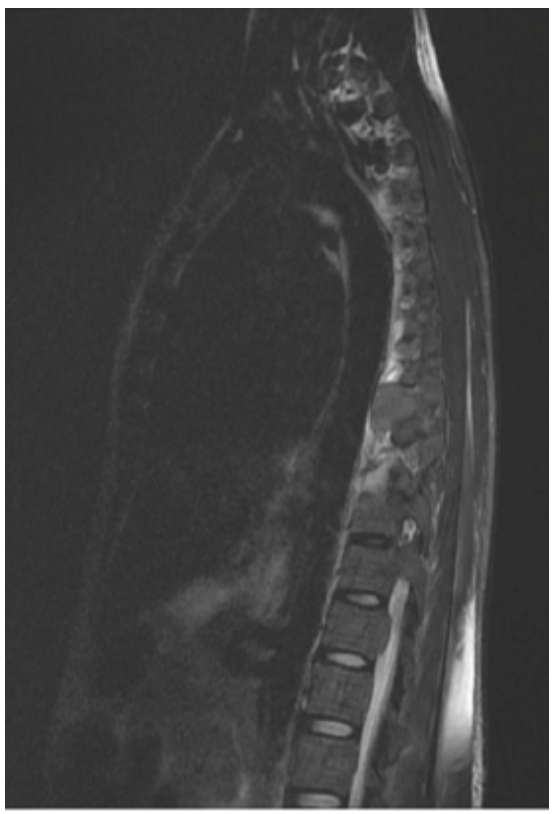

Figure 4. Para-sagittal T2 weighted MRI showing para-spinal soft tissue mass.

hypothesize that sudden clinical manifestation of these lesions might have been precipitated by drop in hemoglobin leading to sudden surge in extra-medullary hematopoiesis. The resultant hyperactivity could have further compressed the spinal nerve roots leading to weakness and loss of sensation of left lower extremity. This hypothesis is plausible by rapid improvement in neurological signs upon stabilization of hemoglobin. It might be argued that the administration of steroids might have had a beneficial role. However, the resolution was too rapid to be attributable to steroids alone. It has been shown that hyper-transfusion therapy helps to shrink extra-medullary hematopoietic tumors and alleviate the compressive effect on spinal cord [3, 5, 6, 9].

In conclusion, acute neurological complications from extra-medullary hematopoietic tissue are rare but serious complications in patients with extreme dyserythropoiesis as a result of beta-thalassemia that might require blood transfusions and high dose steroids. Acute blood loss may lead to surge in extra-medullary hematopoiesis leading to worsening of compressive effects. Therefore in patients with thalassemia undergoing surgery where significant blood loss is anticipated, prophylactic blood transfusions and close monitoring may be necessary to avoid and manage acute neurological complications [4, 6, 9, 18-20].

\section{References}

1. Rund D, Rachmilewitz E. Pathophysiology of alphaand beta-thalassemia: therapeutic implications. Semin

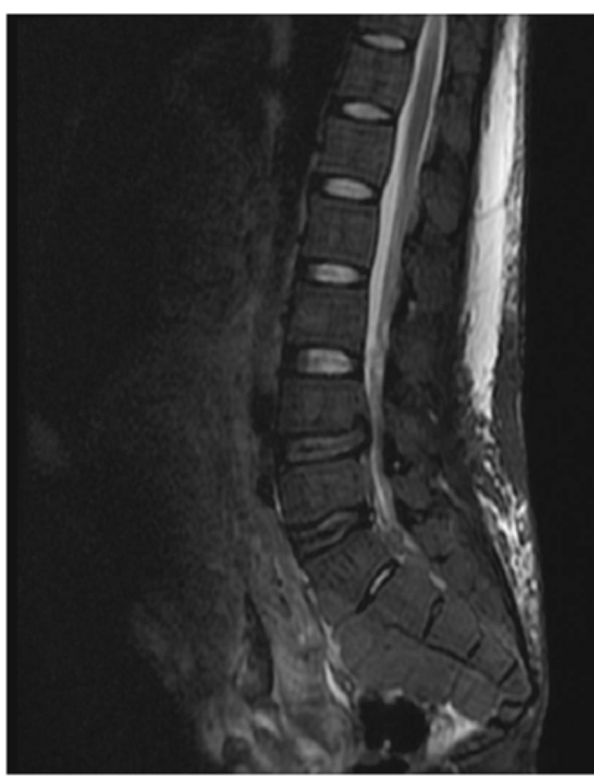

Figure 5. Sagittal T2 weighted MRI showing pre-sacral soft tissue mass originating from sacral marrow with partial destruction of anterior border of sacrum.

Hematol 2001;38(4):343-349.

2. Forget BG. The pathophysiology and molecular genetics of beta thalassemia. Mt Sinai J Med 1993;60(2):95-103.

3. Goerner M, Gerull S, Schaefer E, Just M, Sure M, Hirnle P. Painful spinal cord compression as a complication of extramedullary hematopoiesis associated with beta-thalassemia intermedia. Strahlenther Onkol 2008;184(4):224-226.

4. Salehi SA, Koski T, Ondra SL. Spinal cord compression in beta-thalassemia: case report and review of the literature. Spinal Cord 2004;42(2):117-123.

5. Aliberti B, Patrikiou A, Terentiou A, Frangatou S, Papadimitriou A. Spinal cord compression due to extramedullary haematopoiesis in two patients with thalassaemia: complete regression with blood transfusion therapy. J Neurol 2001;248(1):18-22.

6. Martinez-Rodrigo MA, Sanjuanbenito L, Rodriguez del Barrio E, Martinez-San Millan J, Saldana D. [Spinal cord compression secondary to epidural extramedullary hematopoiesis in thalassemia: a clinical case and review of literature]. Rev Neurol 1998;27(160):998-1004.

7. Mutalimova AB. [Features of cerebrovascular disorders in children with beta-thalassemia major]. Zh Nevropatol Psikhiatr Im S S Korsakova 1975;75(10):1484-1489.

8. Sinniah D, Vignaendra V, Ahmad K. Neurological complications of beta-thalassaemia major. Arch Dis Child 1977;52(12):977-979.

9. Issaragrisil S, Piankigagum A, Wasi P. Spinal cord compression in thalassemia. Report of 12 cases and recommendations for treatment. Arch Intern Med 
1981;141(8):1033-1036.

10. Massenkeil G, Wichmann W, Krummenacher F, Rhyner K. [Reversible spinal cord compression caused by extramedullary hematopoietic foci in thalassemia]. Dtsch Med Wochenschr 1993;118(4):100-106.

11. Aarabi B, Haghshenas M, Rakeii V. Visual failure caused by suprasellar extramedullary hematopoiesis in beta thalassemia: case report. Neurosurgery 1998;42(4):922925; discussion 925-926.

12. Rahman AT, Mannan MA, Sadeque S. Acute and longterm neurological complications in children with acute lymphoblastic leukemia. Bangladesh Med Res Counc Bull 2008;34(3):90-93.

13. Nakajima D, Fukushima K, Yamanouchi H. [Neurological complications during and after the treatment of acute lymphocytic leukemia]. No To Hattatsu 2006;38(3):195200.

14. Pagano L, Marra R, De Stefano V, Di Donfrancesco A, Leone G. [Neurological complications of acute myeloid leukemia in adults]. Minerva Med 1986;77(1-2):13-17.

15. Tantawy AA, Adly AA, Mahdy SA, Kamel GZ. Spinal cord compression and extramedullary hematopoiesis in young Egyptian beta-thalassemia patients. Hemoglobin
2009;33(6):448-462.

16. Cappellini MD, Musallam KM, Taher AT. Insight onto the pathophysiology and clinical complications of thalassemia intermedia. Hemoglobin 2009;33 Suppl 1:S145159.

17. Gamberini MR, Fortini M, De Sanctis V. Paraplegia due to spinal cord compression by extramedullary erythropoietic tissue in a thalassaemia intermedia patient with gynecomastia secondary to cirrhosis: successful treatment with hydroxyurea. Pediatr Endocrinol Rev 2004;2 Suppl 2:316-318.

18. Pistevou-Gompaki K, Skaragas G, Paraskevopoulos P, Kotsa K, Repanta E. Extramedullary haematopoiesis in thalassaemia: results of radiotherapy: a report of three patients. Clin Oncol (R Coll Radiol) 1996;8(2):120-122.

19. Shin KH, Sharma S, Gregoritch SJ, Lifeso RM, Bettigole R, Yoon SS. Combined radiotherapeutic and surgical management of a spinal cord compression by extramedullary hematopoiesis in a patient with hemoglobin $\mathrm{E}$ beta-thalassemia. Acta Haematol 1994;91(3):154-157.

20. Zafeiriou DI, Economou M, Athanasiou-Metaxa M. Neurological complications in beta-thalassemia. Brain Dev 2006;28(8):477-481. 